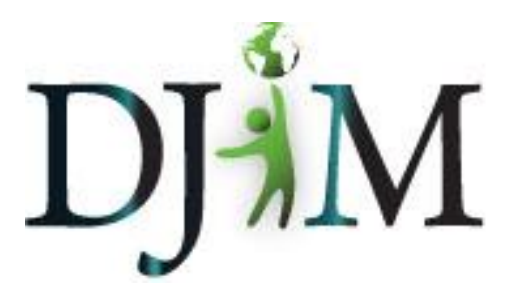

Volume 1 - Spring 2005 djim.management.dal.ca

\title{
Talking Through the Keys
}

\begin{abstract}
About the Author(s): Kenneth Allan is an MLIS student at Dalhousie University. He holds a Bachelor of Arts in History from the University of Alberta in Edmonton. Upon graduation, he is most interested in working in a special or public library and having the opportunity to take on a wide variety of challenges.
\end{abstract}


Lynn Truss's best seller, Eats, Shoots, \& Leaves, is an entertaining book that is also thought provoking. Truss acknowledges that new technologies have contributed to the survival of written language as a form of everyday communication, at the same time she bemoans that written communication has become less artful and thoughtful. She says that e-mails are not really writing, they are "just sending" (p. 192). While new technologies such as e-mail and instant messaging predispose themselves to a less formal style of writing than traditional letterwriting, thoughtful communication is still possible through these mediums.

When letter-writing first began as a means of communication, the time between the writing of the letter and its reading by the recipient could often span weeks or even months. This required the letter-writer to be thoughtful in what he or she had to say. If a colonist in Upper Canada wanted to write a letter to a lord in England, that letter could take weeks to arrive at its destination. The letter-writer had to be thoughtful and judicious in what was said, because every word counted and changing the phrasing of arguments was time-intensive. At the same time, he or she did not need to immediately compose the letter; this gave the letter-writer the time to construct a thoughtful argument, by using turns of phrase and punctuation subtly and thoughtfully to convey his or her point of view.

The advent of faster forms of written communication has also placed demands on letterwriters to respond quickly to written communication. E-mail can be quickly received by the recipient and costs nothing for the sender. This means written communication has become more like conversation, demanding a rapid reaction. Instant messaging, which allows the writer and receiver to respond to each other in seconds, is even more rapid and conversational. To pause for extensive reflection and editing in an instant messaging conversation for any time period longer than a few minutes would make your partner think that you have moved on to another task. Truss laments the arrival of emoticons in her book, and regrets that time once lost to in-person conversation is now lost to electronic communication (p. 192-193). However, this simply shows how modern forms of communication have become faster and cheaper to use; it is necessary for us to make use of them in different and less formal ways.

Truss also implies that, when using e-mail or instant messaging, writers will be less careful about "selecting the right words in the right order" (p. 193), suggesting that communication will somehow be less thoughtful. I disagree, and would suggest that although the manner in which thoughtful communication occurs is changing, thought is still being put into written communication via e-mail and instant messaging. Electronic communication may bear more of a resemblance to conversation than to traditional forms of writing, but thoughtful interaction may still occur. For example, in a recent instant messaging conversation with a friend of mine, we discussed the advantages and disadvantages of Sunday Shopping in Nova Scotia as we waited for the results of the vote to come in. As I would in a conversation, I took a moment to gather and compose my thoughts before I stated my positions. Traditional formal interaction 
may also occur through these new forms of communication. Even today, an official in Canada may send an e-mail to a lord in England. Thinking of his audience, he or she would certainly be as considerate in the message as predecessors in the colony of Canada would have been.

Formality and thoughtfulness in written communication is dependent on the circumstance, audience, and means of communication. While the means in which we express ourselves may have changed to suit the demands of new technology, thoughtful communication in written form is far from dead. Truss's humorous and eloquent book allows us to reflect on these changes. 


\section{Reference}

Truss, Lynne. (2004). Eats, shoots \& leaves. New York: Gotham Books. 